\title{
Structure of the yeast U2/U6 snRNA complex
}

\author{
JORDAN E. BURKE, ${ }^{1}$ DIPALI G. SASHITAL, ${ }^{1,4}$ XIAOBING ZUO, ${ }^{2}$ YUN-XING WANG, $^{3}$ \\ and SAMUEL E. BUTCHER ${ }^{1,5}$ \\ ${ }^{1}$ Department of Biochemistry, University of Wisconsin, Madison, Wisconsin 53706, USA \\ ${ }^{2}$ Advanced Photon Source, Argonne National Laboratory, Chicago, Illinois 60437, USA \\ ${ }^{3}$ National Cancer Institute, National Institutes of Health, Frederick, Maryland 21702, USA
}

\begin{abstract}
The U2/U6 snRNA complex is a conserved and essential component of the active spliceosome that interacts with the pre-mRNA substrate and essential protein splicing factors to promote splicing catalysis. Here we have elucidated the solution structure of a 111-nucleotide U2/U6 complex using an approach that integrates SAXS, NMR, and molecular modeling. The U2/U6 structure contains a three-helix junction that forms an extended " $Y$ " shape. The U6 internal stem-loop (ISL) forms a continuous stack with U2/U6 Helices Ib, Ia, and III. The coaxial stacking of Helix Ib on the U6 ISL is a configuration that is similar to the Domain V structure in group II introns. Interestingly, essential features of the complex-including the U80 metal binding site, AGC triad, and pre-mRNA recognition sites-localize to one face of the molecule. This observation suggests that the U2/U6 structure is well-suited for orienting substrate and cofactors during splicing catalysis.
\end{abstract}

Keywords: NMR; RNA; SAXS; U6 snRNA; spliceosome

\section{INTRODUCTION}

Pre-mRNA splicing, the removal of introns from premRNA, is an essential process in all eukaryotes (Butcher and Brow 2005; Fabrizio et al. 2009; Valadkhan and Jaladat 2010) that proceeds through two transesterification reactions (Padgett et al. 1984). The spliceosome is responsible for pre-mRNA splicing and is composed of a large number of proteins and five small nuclear RNAs (snRNAs): U1, U2, U4, U5, and U6 (Wahl et al. 2009; Egecioglu and Chanfreau 2011). At the heart of the spliceosome is the U2/U6 snRNA complex (Hausner et al. 1990; Madhani et al. 1990; Datta and Weiner 1991; Madhani and Guthrie 1992; Luukkonen and Seraphin 1998), an essential component of the active site of the spliceosome.

The spliceosome has been hypothesized to be a ribozyme (Collins and Guthrie 2000; Butcher 2009) based on mechanistic and structural similarities with the group II selfsplicing intron (Gordon et al. 2000; Keating et al. 2010) and the observation that protein-free U2/U6 complexes derived from the human sequences have residual catalytic activity related to splicing in vitro (Valadkhan and Manley 2001,

\footnotetext{
${ }^{4}$ Present address: Department of Molecular and Cell Biology, University of California, Berkeley, CA 94720, USA.

${ }^{5}$ Corresponding author.

E-mail butcher@biochem.wisc.edu.

Article published online ahead of print. Article and publication date are at http://www.rnajournal.org/cgi/doi/10.1261/rna.031138.111.
}

2003; Valadkhan et al. 2009). These complexes promote inefficient reactions that are chemically similar to the first step of splicing (Valadkhan et al. 2007) and a complete, twostep trans-splicing reaction (Lee et al. 2010). The catalytic activity of the complex is dependent on the presence of $\mathrm{Mg}^{2+}$ (Yu et al. 1995; Lee et al. 2010). U2/U6 specifically binds divalent metal ions in vitro in the context of assembled spliceosomes in the U6 internal stem-loop (ISL) (Yean et al. 2000; Huppler et al. 2002) and the AGC triad (Lee et al. 2010) in U2/U6 Helix Ib (Fig. 1), suggesting a possible twometal ion mechanism (Steitz and Steitz 1993) for splicing catalysis similar to the proposed mechanism of the group II self-splicing intron (Sontheimer et al. 1997; Gordon and Piccirilli 2001; Toor et al. 2008).

The yeast U2/U6 complex has been proposed to form a three-helix junction (Fig. 1) flanked by a series of short helical segments connected by internal loops and bulges (Madhani and Guthrie 1992). The three-helix junction is made up of the U6 internal stem-loop (ISL) and U2/U6 intermolecular Helices I and II and is linked by a uracil-rich loop (Fig. 1; Madhani and Guthrie 1992). The U6 ISL is highly conserved (Fortner et al. 1994) and contains an essential metal binding site at U80 (Fig. 1; Huppler et al. 2002; Reiter et al. 2003; Blad et al. 2005; Lee et al. 2010). Helix I is essential for splicing (Madhani and Guthrie 1992) and contains the invariant AGC triad. Base-pairing in Helix Ib (Fig. 1) between the AGC triad and U2 is important for both steps of splicing (Hilliker and Staley 2004; Mefford and Staley 2009). The internal loop 


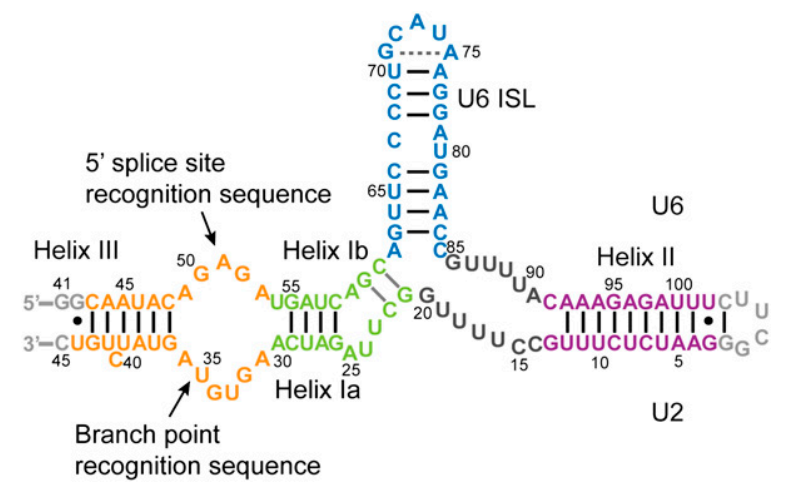

FIGURE 1. Proposed secondary structure of a 111-nt RNA based on the S. cerevisiae U2/U6 RNA complex (Madhani and Guthrie 1992). Structural features are Helix I (green), Helix II (purple), Helix III and an internal loop that binds to $5^{\prime}$ splice site and branch point (orange), U6 ISL (blue), U-rich loop (dark gray), and non-native sequences (light gray). (Black lines or circles) Experimentally determined base pairs (see Fig. 4).

between Helix I and Helix III is composed of essential motifs in U6 and U2 that base-pair to the $5^{\prime}$ splice site and the branch point of the pre-mRNA substrate, respectively, to promote the first step of splicing (Fig. 1; Wassarman and Steitz 1992). This loop is closed by a third intermolecular helix (Helix III), which has been detected in vivo in mammalian cells (Fig. 1; Sun and Manley 1995). While genetic evidence suggests formation of a three-helix junction in U2/U6, NMR studies of several truncated versions of the U2/U6 complex (Sashital et al. 2004) demonstrated formation of a four-helix junction conformation. A statistical mechanical analysis of the U2/U6 free-energy landscape predicted that the three-helix junction secondary structure has a more favorable free energy, but that the four-helix junction conformation would dominate in the presence of favorable coaxial stacking interactions (Cao and Chen 2006). MFOLD (Zuker 2003) predicts four different secondary structures for the yeast U2/U6 complex that have very similar free energies $(-34.4 \leq \Delta G \leq-33.1)$. Therefore, identification of the correct secondary structure from several predicted structures is highly challenging in the absence of direct experimental data.

Very little is known about the tertiary structure of the U2/U6 complex. Structural studies of the U6 ISL by NMR (Huppler et al. 2002; Venditti et al. 2009) reveal that the ISL contains a 3-nucleotide (nt) internal loop containing a conserved metal binding site at the phosphate of U80. The base of U80 stacks into the helix in the presence of divalent metal ions (Blad et al. 2005). This conformation involves formation of a highly dynamic C67-U80 pair that is modulated by the protonation state of A79, which can form a competing C67-A79 base pair (Venditti et al. 2009). Additionally, hydroxyl radical experiments indicate that U80 is proximal to the $5^{\prime}$-splice site in the spliceosome (Rhode et al. 2006). Helix I has also been proposed to interact with the $5^{\prime}$-splice site (Ryan et al. 2004). Cross-linking studies have revealed possible contacts between the pre-mRNA binding site and the UA bulge of Helix I as well as U-rich sequences within the three-helix junction (Fig. 1; Madhani and Guthrie 1994; Valadkhan and Manley 2000; Ryan et al. 2004). Additionally, single-molecule FRET studies have demonstrated that the pentaloop of the U6 ISL and Helix III are distal in the presence of $\mathrm{Mg}^{2+}$ (Guo et al. 2009).

Due to apparent structural and mechanistic similarities between the spliceosome and the group II self-splicing intron (Gordon et al. 2000), a tertiary structure model has been proposed for U2/U6 that infers long-range contacts based on those present in the crystal structure of the group II intron (Keating et al. 2010). In the proposed model, two base-triples form a metal binding platform that constitutes the active site (Toor et al. 2008; Keating et al. 2010). The basetriples are formed through interaction of U80 in the U6 ISL and a residue in the $5^{\prime}$ splice site recognition sequence with the major groove of Helix Ib. A recent study demonstrated that the first step of the group II intron reaction is more efficient in the presence of a linking oligonucleotide that holds the branch site and the $5^{\prime}$-splice site in close proximity, similar to the function of U2/U6 Helix III ( $\mathrm{Li}$ et al. 2011). Still, it remains unclear how all of these elements function together during the splicing reaction.

Here we present the structure of a 111-nt U2/U6 snRNA complex in solution as analyzed by small-angle $\mathrm{X}$-ray scattering (SAXS) and NMR. We used a novel method in which a large number of starting structural models generated with MC-Sym (Parisien and Major 2008) were sorted by agreement with the experimental NMR and SAXS data. The structural models in best agreement with both data sets were jointly refined against SAXS and NMR data by restrained molecular dynamics and energy minimization. The resulting U2/U6 complex has a well-defined fold that provides new insight into its role as an essential component of the spliceosome active site.

\section{RESULTS}

\section{Global structure of the $S$. cerevisiae U2/U6 complex}

To investigate the structure of the U2/U6 complex, we used a 111-nt RNA construct (hereafter referred to as U2/U6) that contains the entire base-paired region of the $S$. cerevisiae U2/U6 snRNA complex linked by a UUCG tetraloop on Helix II to ensure proper stoichiometry of the U2 and U6 strands (Fig. 1). The global fold of U2/U6 in $150 \mathrm{mM} \mathrm{NaCl}$ and in the presence and absence of $\mathrm{MgCl}_{2}$ was determined by small-angle X-ray scattering (SAXS). The Kratky profile exhibits two peaks, which are indicative of a well-defined, nonglobular conformation (Fig. 2A). The $p(r)$ plot (Fig. 2B) contains a peak at $20 \AA$ that corresponds to A-form helical width and another at $40 \AA$ that may correspond to helical length. The structure of the U6 ISL is $40 \AA$ in length (Venditti et al. 2009), and a model of Helix II generated using the MC- 

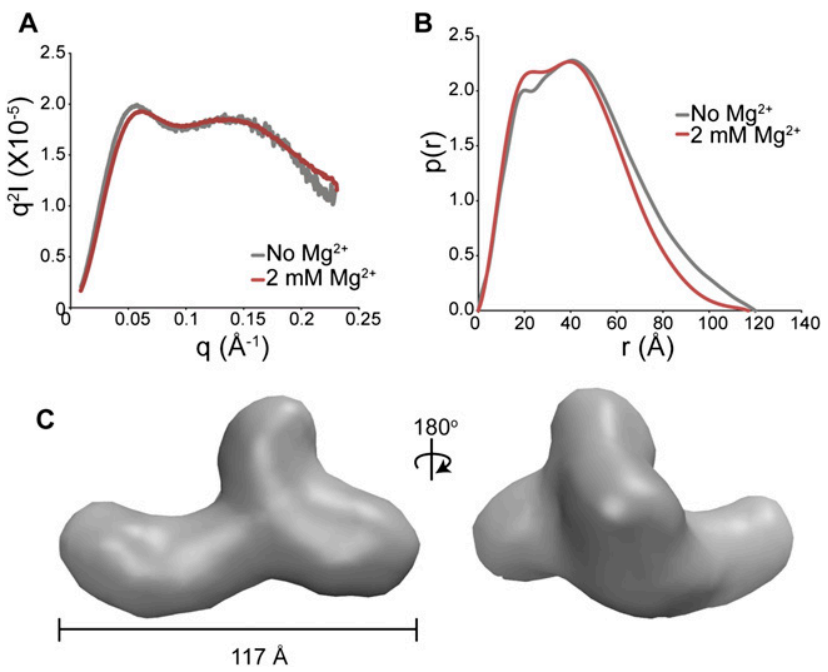

FIGURE 2. Small-angle X-ray scattering of U2/U6. (A) Kratky profile of the U2/U6 complex in the absence and presence of $\mathrm{Mg}^{2+}$. All experiments were conducted in $50 \mathrm{mM}$ Tris $(\mathrm{pH} 7.0), 150 \mathrm{mM}$ sodium chloride, and 0 or $2 \mathrm{mM}$ magnesium chloride. (B) Pair distance distribution function plot of U2/U6 in the absence and presence of $\mathrm{Mg}^{2+}$. (C) Ab initio structure of $\mathrm{U} 2 / \mathrm{U} 6$ in $2 \mathrm{mM}$ magnesium chloride. Twenty structures were generated using the program DAMMIF and then averaged with DAMAVER, yielding a normalized spatial discrepancy (NSD) of 0.85 .

Fold/MC-Sym pipeline (Parisien and Major 2008) measures $44 \AA$ in length. Both features are still visible in the $p(r)$ plot upon addition of $2 \mathrm{mM} \mathrm{MgCl}$; however, the increase in the peak intensity at $20 \AA$ (Fig. 2B) likely results from helical stabilization by $\mathrm{Mg}^{2+}$. In $150 \mathrm{mM} \mathrm{NaCl}$, the radius of gyration $\left(R_{\mathrm{g}}\right)$ of the U2/U6 RNA is $37 \AA$, and the maximum dimension $\left(D_{\text {max }}\right)$ is $120 \AA$. Upon addition of $2 \mathrm{mM} \mathrm{MgCl}_{2}$, the $R_{\mathrm{g}}$ and $D_{\max }$ are slightly smaller-34 $\AA$ and $117 \AA$, respectively (Table 1 ) - indicating that $\mathrm{Mg}^{2+}$ causes only a slight compaction of U2/U6 and not a large-scale change in structure. Higher $p(r)$ values between 60 and $117 \AA$ in the absence of $\mathrm{Mg}^{2+}$ are suggestive of increased structural heterogeneity. Addition of higher $\mathrm{MgCl}_{2}$ concentration $(10 \mathrm{mM})$ did not result in further compaction of the structure (Table 1).

Based on SAXS data collected in $150 \mathrm{mM} \mathrm{NaCl}$ and $2 \mathrm{mM}$ $\mathrm{MgCl}_{2}$, we calculated an ab initio model of U2/U6 using the program DAMMIF (Franke and Svergun 2009). The lowresolution model reveals that U2/U6 forms a "Y" shape in solution (Fig. 2C) composed of three arms roughly the size of A-form helices. The extended shape of the molecule is consistent with the Kratky profile and the $p(r)$ plot. To elucidate the locations of helices within the ab initio envelope, we performed SAXS on RNA constructs containing 11-12-bp helical extensions of Helix II or III (Fig. 3A,B) with non-native secondary structure. The helical extensions manifest as additional envelope density adjacent to the corresponding helix. Thus, the extended constructs allow identification of Helix II and Helix III (Fig. 3C,D), while the unperturbed helical feature likely belongs to the U6 ISL.

\section{NMR spectroscopy of U2/U6 RNA}

NMR spectroscopy was used to investigate the 111-nt U2/U6 RNA structure in $10 \mathrm{mM} \mathrm{K}^{+} \mathrm{PO}_{4}{ }^{-}(\mathrm{pH} 7.0)$, with and without $2 \mathrm{mM} \mathrm{MgCl}$. Secondary structure was determined by two-dimensional (2D) ${ }^{1} \mathrm{H}-{ }^{1} \mathrm{H}$ NOESY (Fig. 4) and ${ }^{1} \mathrm{H}-{ }^{15} \mathrm{~N}$ TROSY-HSQC (Fig. 5A). Addition of $2 \mathrm{mM}$ $\mathrm{MgCl}_{2}$ does not change the secondary structure of the molecule as evidenced by $2 \mathrm{D}{ }^{1} \mathrm{H}-{ }^{1} \mathrm{H}$ NOESY and ${ }^{1} \mathrm{H}-{ }^{15} \mathrm{~N}$ TROSY-HSQC (data not shown). In addition, the secondary structure of a bimolecular U2/U6 complex lacking the UUCG tetraloop linker in $10 \mathrm{mM} \mathrm{K}^{+} \mathrm{PO}_{4}^{-}$( $\mathrm{pH} 7.0$ ), and $100 \mathrm{mM} \mathrm{KCl}$ is consistent with the structure of the linked RNA construct (data not shown), demonstrating that the presence of the linker and changes in monovalent salt conditions do not influence the structure of the complex.

Nearly all base-paired imino resonances in the RNA could be assigned (Fig. 4), with the exception of those that are at effective helical ends and exchange rapidly with solvent. The U6 ISL and Helix I were assigned based on chemical shift similarity with previously determined structures of the isolated U6 ISL domain (Huppler et al. 2002) and a 24-nt Helix I construct (PDB ID 2LK3), respectively. Sequential NOEs indicate formation of Helix III, Helix Ia, the U6 ISL, and Helix II (Fig. 4). Imino resonances were unambiguously assigned based on ${ }^{1} \mathrm{H}-{ }^{1} \mathrm{H}$ NOESY and ${ }^{1} \mathrm{H}-{ }^{15} \mathrm{~N}$ TROSY-HSQC experiments, with the exception of two $\mathrm{G}$ imino resonances. These resonances have hydrogenbonded ${ }^{1} \mathrm{H}$ and ${ }^{15} \mathrm{~N}$ chemical shifts indicative of WatsonCrick base-pairing (Fig. 5A), although any potential NOE between them is obscured by the diagonal due to their similar ${ }^{1} \mathrm{H}$ chemical shifts. However, the only remaining unassigned helical G imino protons belong to U2-G21 and U6-G60 in Helix Ib, so by process of elimination we can tentatively assign these resonances to U2-G21 and U6-G60 in Helix Ib. These assignments are also consistent with the chemical shifts of these iminos in the isolated Helix I RNA (BMRB code 17972).

The chemical shifts of the U6 ISL are identical to those previously determined for the isolated U6 ISL (Fig. 5B; Huppler et al. 2002; Venditti et al. 2009), indicating that the U6 ISL is folded in an identical manner to the previously determined structure and further suggesting that it does not participate in stable tertiary contacts. All of the base pairs in Helix II are observed with the exception of the last C-G pair (Fig. 4). The adjacent uracil nucleotides (U2:U16-19 and

TABLE 1. SAXS measurements of the 111-nt U2/U6 RNA

\begin{tabular}{lcc}
\hline Condition & $R_{\mathrm{g}}(\AA)$ & $D_{\max }(\AA)$ \\
\hline $\mathrm{No} \mathrm{Mg}^{2+}$ & 37.3 & 120 \\
$2 \mathrm{mM} \mathrm{Mg}^{2+}$ & 34.0 & 117 \\
$10 \mathrm{mM} \mathrm{Mg}^{2+}$ & 35.6 & 118 \\
\hline
\end{tabular}


A
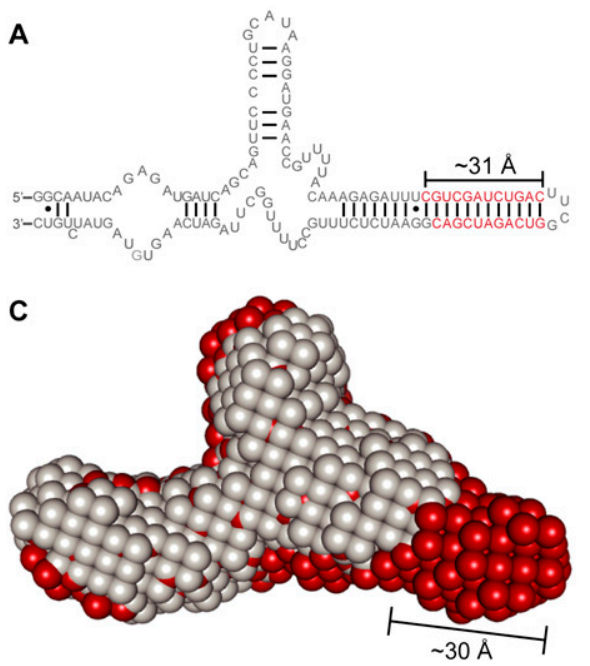

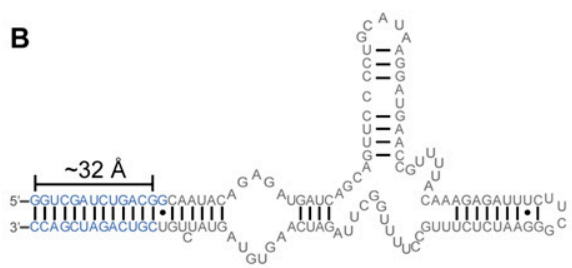

D

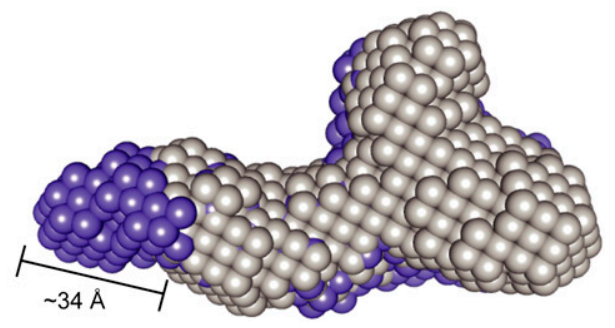

FIGURE 3. Identification of helices within the U2/U6 envelope. Helical extensions of 11 bp on Helix II ( $A$, in red) or 12 bp on Helix III (B, in blue) were added to the original 111-nt RNA. Lengths of the helical extensions were estimated based on 3D models generated using the MC-Fold/ MC-Sym pipeline (Parisien and Major 2008). The ab initio model containing extended Helix II ( $C$, red); the model containing extended Helix III ( $D$, blue); the original RNA (gray).

U6:U87-90) have resonances that are observable in the onedimensional (1D) ${ }^{1} \mathrm{H}$ NMR spectrum (Fig. 4) and also in the ${ }^{1} \mathrm{H}-{ }^{15} \mathrm{~N}$ TROSY-HSQC (Fig. 5A); however, these resonances are not visible in the NOESY spectrum, indicating that they exchange with water during the 100-msec mixing time. Therefore, these uracil residues are not involved in stable base-pair interactions but may interact transiently with each other, consistent with their chemical shifts, which are diagnostic for U-U wobble pairs (Theimer et al. 2003; $\mathrm{Du}$ et al. 2004). Transient formation of such pairs across the U-rich loop may effectively extend Helix II (Fig. 1).

Base-pairing is also observed throughout Helix III (Fig. 4). Observation of the NOE cross-peak between U2-U40 and U2-U42 (Fig. 4) indicates that U2-C41 is flipped out of the helix, allowing the flanking base pairs to stack. There are no observable imino protons corresponding to the large internal loop containing the $5^{\prime}$-splice site and branch-point recognition sequences (Figs. 1, 5A). Therefore, stable basepairing interactions involving imino protons do not form across this loop.

\section{Modeling the structure of the U2/U6 snRNA complex in solution}

All-atom structural models of U2/U6 were generated using MC-Sym (Parisien and Major 2008) based on the secondary structure determined by NMR. Twenty-five hundred models were filtered based on goodness of fit ( $\chi^{2}$ agreement) between the predicted small-angle X-ray scattering amplitudes for each model and the experimental data (Fig. $6 \mathrm{~A})$. The $25 \%$ of structures with the best $\chi^{2}$ values $(<2.57)$ were then tested for agreement with ${ }^{1} \mathrm{H}-{ }^{15} \mathrm{~N}$ RDC measurements. Only those models with a $\mathrm{Q}$ factor (Bax et al.
1998) of $<0.35$ were accepted (Table 2), resulting in 10 structural models that fit well to both SAXS and NMR data (Fig. 6A,B).

The 10 selected models were then subjected to normal mode analysis (NMA) as previously described (Kazantsev et al. 2011) to ensure that conformational space has been adequately sampled and that the models were not trapped in a local energetic minimum. Comparison of the predicted scattering curves of the states obtained from NMA with experimental SAXS data resulted in reselection of the original states, leading to the conclusion that the originally selected models reflect the true ground-state conformation of U2/U6 (data not shown). Finally, the 10 structural models were refined simultaneously against SAXS and RDC measurements using restrained molecular dynamics and energy minimization in XPLOR-NIH as previously described (Zuo et al. 2010).

The final structures display excellent agreement between the predicted scattering profiles of the models and the experimental data (Fig. 6C), with a goodness-of-fit $\chi^{2}$ value of $<0.94$ (Table 2). Additionally, there is excellent agreement between the predicted and observed RDC measurements (Fig. 6D) with $\mathrm{Q}$ factor values of 0.12 or less (Table 2 ). The 10 lowest energy structures have a global backbone RMSD of $2.1 \AA$ (Table 3). All individual A-form regions have RMSD values of $0.9-1.7 \AA$, while single-stranded regions have higher RMSD values of 2.5-3.0 (Table 3).

The conformation of the refined structural models of U2/U6 is entirely consistent with the ab initio model generated from SAXS data alone (Fig. 7A), and our independent SAXS analysis of the extended constructs corroborates the positioning of the helices around the three-helix junction (Fig. 3). The U6 ISL, Helix I, and Helix III form a continuous 


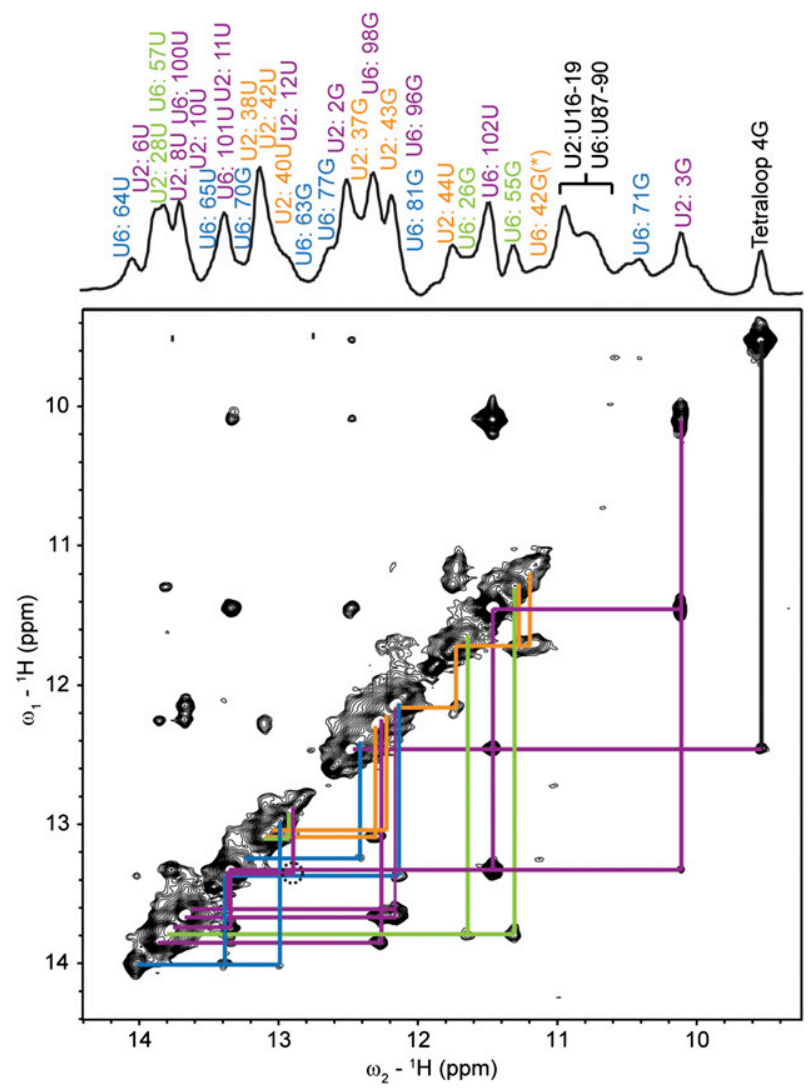

FIGURE 4. Secondary structure of a 111-nt U2/U6 RNA as determined by NMR. $1 \mathrm{D}{ }^{1} \mathrm{H}$ spectrum and $2 \mathrm{D}{ }^{1} \mathrm{H}-{ }^{1} \mathrm{H}$ NOESY of the U2/U6 complex in $20 \mathrm{mM}$ potassium phosphate ( $\mathrm{pH}$ 7.0). Assignments and connecting lines are color-coded according to secondary structure, as in Figure 1. The NOE peak between U2-U12 and U2-G13 is only visible at a lower contour level and is therefore indicated with a dashed circle. Base pairs confirmed by ${ }^{1} \mathrm{H}-{ }^{1} \mathrm{H}$ 2D NOESY are indicated in Figure 1 by black lines or circles, while base pairs inferred by chemical shift agreement are indicated with gray lines.

stack (Fig. 7B), resulting in a large distance between the pentaloop of the U6 ISL and $5^{\prime}$ end of Helix III $(\sim 65 \AA)$ that is consistent with single-molecule FRET studies of the U2/U6 complex (Guo et al. 2009). The unpaired uracil residues in the junction region are close enough to form transient interactions such as $\mathrm{U}-\mathrm{U}$ wobble pairs, which would be consistent with the peaks observed in the $2 \mathrm{D}{ }^{1} \mathrm{H}-{ }^{15} \mathrm{~N}$ TROSY-HSQC (Fig. $5 \mathrm{~A}$ ) and the $\sim 20 \AA$ width of the SAXS envelope in this region. However, the uracil residues in the linker were left unrestrained in the structural models and therefore appear disordered in the structure.

\section{DISCUSSION}

Analysis of the structure of U2/U6 by NMR presented unique challenges due to its relatively large size $(36 \mathrm{kDa})$ and extended shape. Therefore, we used a combined approach that integrates the complementary biophysical techniques of SAXS and NMR along with state-of-the-art molecular modeling tools (MC-Sym) (Parisien and Major 2008) to generate structural models. Additionally, refinement of allatom models against both SAXS and RDC measurements resolves degeneracies inherent in both techniques, as previously demonstrated (Grishaev et al. 2008; Wang et al. 2009).

Here we report the experimentally determined secondary structure of the U2/U6 complex (Figs. 4, 5A). U2/U6 is predicted to have multiple energetically similar alternative folds (Cao and Chen 2006). Previously, we observed an alternate secondary structure involving a four-helix junction for truncated versions of the U2/U6 sequence (Sashital et al. 2004). This secondary structure is similar to the human U2/U6 conformation, which is typically depicted as a fourhelix junction (Sun and Manley 1995). In larger constructs, we observe a three-helix junction, which is consistent with extensive genetic studies (Madhani and Guthrie 1992; Hilliker and Staley 2004; Mefford and Staley 2009). Previously studied U2/U6 constructs were truncated in either Helix I, Helix II, or both (Sashital et al. 2004), whereas the 111-nt construct studied here contains the full-length helices. We hypothesize that destabilization of the flanking helices promotes formation of the competing U2 Stem I structure
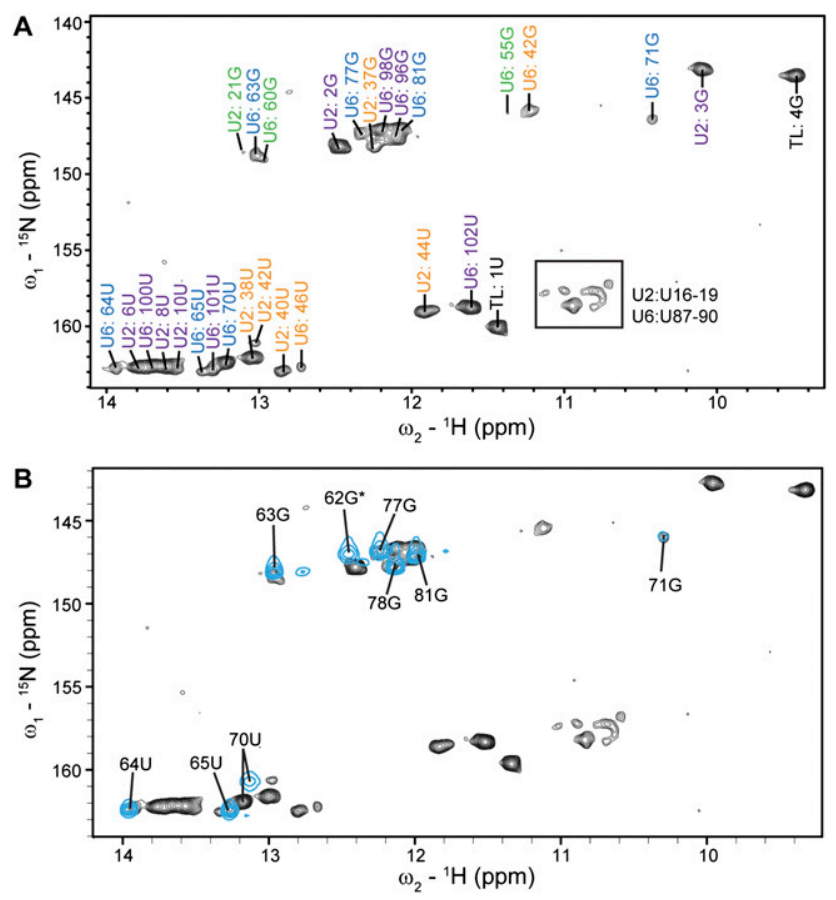

FIGURE 5. ${ }^{1} \mathrm{H}$ and ${ }^{15} \mathrm{~N}$ imino chemical shift assignments for U2/U6. (A) ${ }^{1} \mathrm{H}-{ }^{15} \mathrm{~N}$ TROSY-HSQC experiment in $10 \mathrm{mM}$ potassium phosphate ( $\mathrm{pH}$ 7.0). Helix I (green); Helix II (purple); Helix III (orange); U6 ISL (blue); linker sequences (black). (B) Agreement between chemical shifts for the U6 ISL (blue) (Venditti et al. 2009) and the 111-nt U2/U6 RNA (dark gray). Labels are connected to both peaks for each residue by black lines, except for G62 ${ }^{*}$ ), which is not present in U2/U6. All chemical shifts are identical with the exception of U70, which is adjacent to the pentaloop and is highly sensitive to salt conditions. 

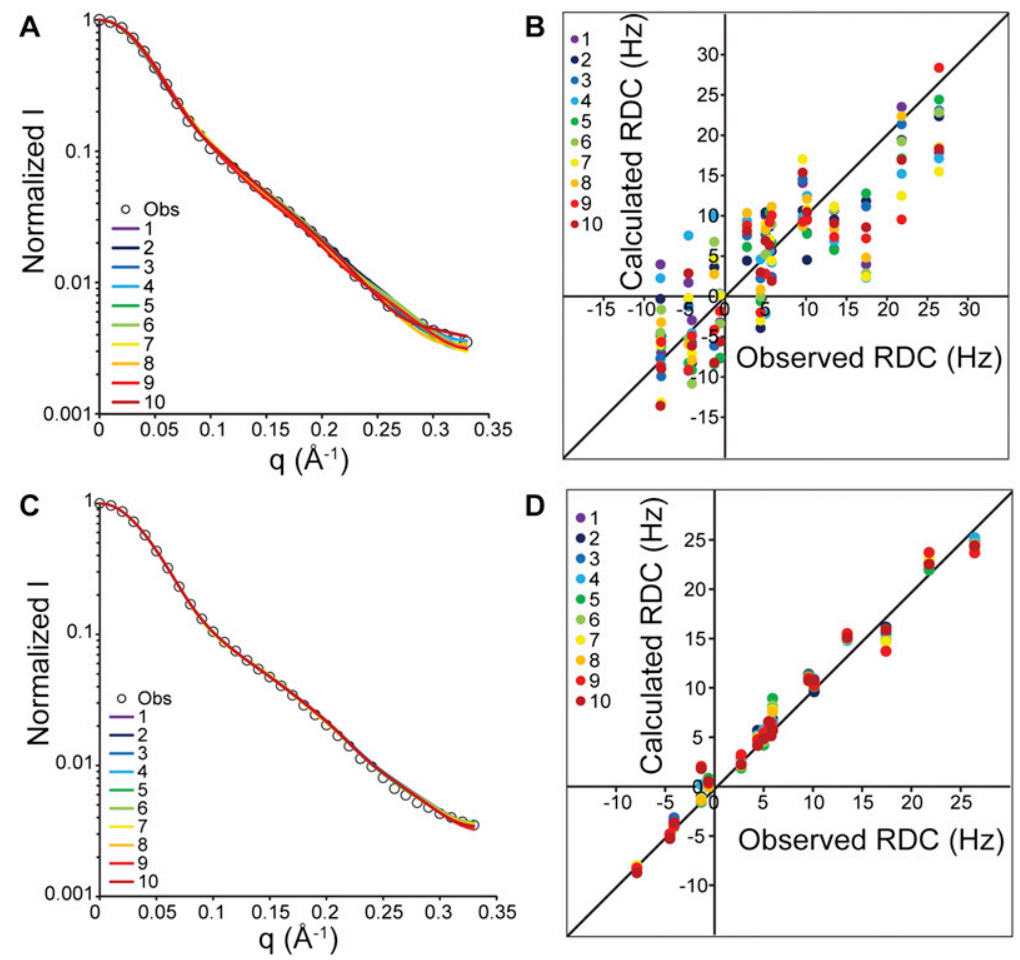

FIGURE 6. Refinement of structural models against SAXS and RDC measurements. $(A)$ The 10 best models of 2500 generated by MC-Sym were selected based on agreement with SAXS and RDC measurements. Predicted (solid lines) and experimental (black circles) scattering profiles of the unrefined models diverge at $q>0.25 \AA^{-1}$. (B) Experimentally measured RDC measurements and calculated RDC values for the unrefined models agree with Q factors of $<0.35$. (C) The 10 selected models were further refined against SAXS data, base-pairing restraints, and RDC measurements by simulated annealing in XPLOR-NIH, significantly improving the fit to the SAXS data at $>0.25 \AA^{-1}$. (D) Refinement improves the RDC Q factor to $<0.15$ for all models.

observed in the four-helix junction (Sashital et al. 2004). Thus, the stability of Helices I and II is likely an important factor for formation of the three-helix junction conformation.

We also observe formation of Helix III for the first time in the $S$. cerevisiae sequence. Based on cross-linking results, Helix III has been proposed to form in the human spliceosome (Sun and Manley 1995). We do not observe the formation of any stable base pairs in the loop between Helix I and Helix III. Because such base-pairing interactions would preclude pairing with the pre-mRNA substrate, maintaining a dynamic or open structure in this region may be important for function.

The three-helix junction secondary structure of U2/U6 forms the basis for the overall "Y" shape of the RNA. Threeway junctions have been found to assume a well-defined configuration of helices based on the length of linker sequences within the junction (Lescoute and Westhof 2006). This configuration defines the 3D topology of the RNA and can either facilitate or prevent long-range tertiary contacts. In U2/U6, the covalent connection between Helix Ib and the U6 ISL results in a continuous stack, which manifests as a long axis composed of Helices I and III and the ISL. Helix I exhibits a linear, coaxially stacked conformation due to extrusion of a 2-nt bulge between Helices Ia and Ib. Based on a nearest-neighbor rule (Xia et al. 1998), formation of isolated Helix Ib is not energetically favorable $\left(\Delta G^{37^{\circ} \mathrm{C}} \sim\right.$ $0.1 \mathrm{kcal} / \mathrm{mol}$ in $1 \mathrm{M} \mathrm{NaCl}$ ). Therefore, the stacking interactions we observe in U2/U6 may be important for stabilizing Helix $\mathrm{Ib}$ in the context of the active spliceosome. The coaxial stacking interaction between Helix Ib and the U6 ISL also determines the relative twist of the helices that positions the U80 metal binding site on the same face as other essential elements in U6 (Fig. 7D).

The conformation of the U2/U6 complex is consistent with the previously determined structures of the isolated U6 ISL (Huppler et al. 2002; Venditti et al. 2009) and Helix I (PDB ID 2LK3). Additionally, the bulge region of Helix I is known to cross-link to the $5^{\prime}$-splice site recognition sequence (U6-G52) in both the S. cerevisiae (Ryan et al. 2004) and human sequences (Valadkhan and Manley 2000). U6-G52 has also been observed to have a genetic interaction with the Helix I bulge in S. cerevisiae (Madhani and Guthrie 1994). This observation led to the proposal that U6-G52 forms a mismatch pair with U2-A25 (Madhani and Guthrie 1994). We find that backbone phosphates of these residues are $\sim 16 \AA$ apart in the structural models of U2/U6 (Fig. 7D), although the bases are not oriented toward one another in our model. However, modeling exercises suggest that flipping these bases out of their respective helices would allow them to come within van der Waals contact distance of each other (data not shown).

TABLE 2. Filtering and refinement statistics of structural models of U2/U6

RDC Q RDC $R^{2}$ SAXS $\chi^{2}$

Model RDC Q RDC $R^{2}$ SAXS $\chi^{2}$ (refined) (refined) (refined)

\begin{tabular}{lllllll}
\hline 1 & 0.32 & 0.79 & 2.0 & 0.07 & 0.99 & 0.87 \\
2 & 0.31 & 0.88 & 1.8 & 0.07 & 0.99 & 0.85 \\
3 & 0.24 & 0.93 & 1.7 & 0.07 & 0.99 & 0.86 \\
4 & 0.29 & 0.67 & 2.2 & 0.08 & 0.99 & 0.94 \\
5 & 0.31 & 0.92 & 0.8 & 0.09 & 0.99 & 0.93 \\
6 & 0.26 & 0.84 & 2.0 & 0.08 & 0.99 & 0.89 \\
7 & 0.24 & 0.77 & 1.6 & 0.08 & 0.99 & 0.91 \\
8 & 0.29 & 0.85 & 2.0 & 0.07 & 0.99 & 0.86 \\
9 & 0.31 & 0.87 & 1.1 & 0.12 & 0.99 & 0.63 \\
10 & 0.25 & 0.88 & 1.5 & 0.09 & 0.99 & 0.65 \\
\hline
\end{tabular}


TABLE 3. Structural statistics for U2/U6

\begin{tabular}{|c|c|}
\hline \multicolumn{2}{|l|}{ Restraints } \\
\hline Distances $^{\mathrm{a}}$ & 818 \\
\hline Dihedral angles $(\mathrm{DIH})^{\mathrm{a}}$ & 644 \\
\hline P-P distances ${ }^{b}$ & 39 \\
\hline Hydrogen-bonded base pairs ${ }^{\mathrm{c}}$ & 35 \\
\hline RDC & 18 \\
\hline Molecular envelope size ${ }^{\mathrm{d}}$ & 10 \\
\hline \multicolumn{2}{|l|}{ Deviations from idealized covalent geometry } \\
\hline Bond $(\AA)$ & $0.006 \pm 0.0005$ \\
\hline Angle $\left(^{\circ}\right)$ & $0.97 \pm 0.02$ \\
\hline Improper $\left({ }^{\circ}\right)$ & $0.75 \pm 0.03$ \\
\hline \multicolumn{2}{|l|}{ RMSD to restraints } \\
\hline $\mathrm{DIH}\left({ }^{\circ}\right)$ & $3.6 \pm 0.1$ \\
\hline $\operatorname{NOE}(\AA)$ & $0.033 \pm 0.002$ \\
\hline $\mathrm{RDC}(\mathrm{Hz})$ & $2.0 \pm 0.1$ \\
\hline \multicolumn{2}{|l|}{ Energies } \\
\hline Total & $-2.1 \pm 0.2 \times 10^{3}$ \\
\hline DIH & $510 \pm 40$ \\
\hline NOE & $610 \pm 70$ \\
\hline RDC & $70 \pm 10$ \\
\hline SAXS & $70 \pm 10$ \\
\hline \multicolumn{2}{|l|}{ Backbone RMSD relative to mean structure $(\AA)$} \\
\hline Global & 2.1 \\
\hline Helix I (residues 14-21, 87-96) & 0.9 \\
\hline Helix II (residues 52-62, 69-79) & 1.2 \\
\hline Helix III (residues $1-8,103-111$ ) & 1.7 \\
\hline U6 ISL (residues 22-45) & 1.3 \\
\hline U loops (residues 46-51, 80-86) & 3.0 \\
\hline Helix I-III loop (residues 9-13, 97-102) & 2.5 \\
\hline UUCG tetraloop (residues 64-67) & 1.1 \\
\hline \multicolumn{2}{|c|}{ 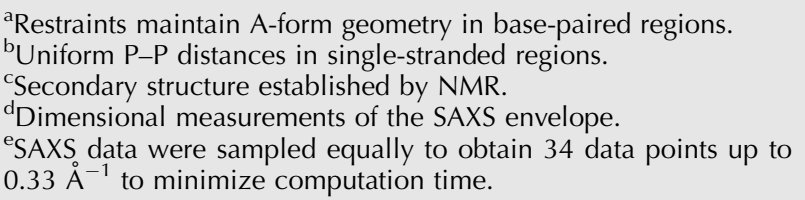 } \\
\hline
\end{tabular}

U2/U6 has been frequently compared with the group II intron based on mechanistic and structural similarities (Gordon et al. 2000); however, formation of the group II intron active site is dependent on an extensive network of stabilizing RNA tertiary interactions including kissing loops and tetraloop-receptor interactions (Toor et al. 2008). The vast size difference between the conserved portions of the U2/U6 complex and even the smallest group II introns implies that other components are responsible for these stabilizing interactions in the spliceosome. Protein splicing factors likely play a large role in buttressing RNA interactions in the active site of the spliceosome. While we observe stacking between Helix Ib and the U6 ISL similar to the structure of domain V of the group II intron, we do not observe formation of analogous base-triple interactions that constitute the group II intron active site. Nevertheless, it is interesting that highly conserved motifs in U6 snRNA, including the AGC triad, the $5^{\prime}$-splice site recognition sequence, and the U80 metal binding site align to one face of the U2/U6 complex. In the mammalian spliceosome, the nucleotide equivalent to U80 approaches the $5^{\prime}$-splice site at least some of the time (Rhode et al. 2006), as indicated by hydroxyl radical experiments that can diffuse over distances of up to $24 \AA$ (Han and Dervan 1994). Additionally, in a construct containing sequences from the yeast U2/U6 complex, smFRET studies demonstrate that the U6 ISL approaches Helix III at concentrations of $\mathrm{MgCl}_{2}$ of $10 \mathrm{mM}$ or greater (Guo et al. 2009). However, we observe that U80 is distal to the $5^{\prime}$-splice site recognition sequence, and detect no large-scale conformational change by SAXS in the presence of $10 \mathrm{mM} \mathrm{MgCl}$. Possibly, the discrepancy between these studies is related to differences in the RNA sequences investigated. In the spliceosome, the U6 ISL and Helix III regions may come into closer proximity upon activation, which occurs in the presence of the pre-mRNA substrate and also a multitude of protein splicing factors (Wahl et al. 2009). This is consistent with the observation that the mammalian sequence of U2/U6 has a very low level of catalytic activity in the absence of protein (Valadkhan and Manley 2001, 2003; Valadkhan et al. 2007, 2009; Lee et al. 2010).

The hypothesis that protein and substrate are required for a catalytically active conformation is also consistent with the kinetic proofreading model of spliceosome activation (Smith et al. 2008). During this process, several $\mathrm{DEXD} / \mathrm{H}$ box helicases are necessary for rearrangement of interactions between the substrate and mRNAs. A large number of regulatory steps must occur before spliceosome activation is possible, during which pauses allow for non-ideal pre-mRNA substrates to be discarded (Smith et al. 2008). A ground-state "inactive" conformation of U2/U6 during the final stages of activation may allow for such a pause before the first step of splicing and then again before the second step as the $3^{\prime}$ splice site is positioned (Konarska et al. 2006). The extended conformation we observe may represent such a ground-state structure.

Alternatively, the face containing the essential elements of U6 could represent a protein-binding scaffold. The U5 snRNP protein Prp8 has been observed to cross-link to both the pre-mRNA substrate and the U6 snRNA at the $5^{\prime}$-splice site (Reyes et al. 1999; Vidal et al. 1999). The 5'splice site consensus sequence and the $5^{\prime}$-splice site recognition sequence of U6 form an unstable complex (Valadkhan et al. 2007). A protein factor such as Prp8 may assist stabilization of the pre-mRNA/U6 complex during the first step of splicing. In this case, the large cleft between the U6 ISL and the pre-mRNA binding site could accommodate both the substrate and a protein factor.

Here we have investigated the ground-state structure of the U2/U6 complex. We developed a method for analysis of 

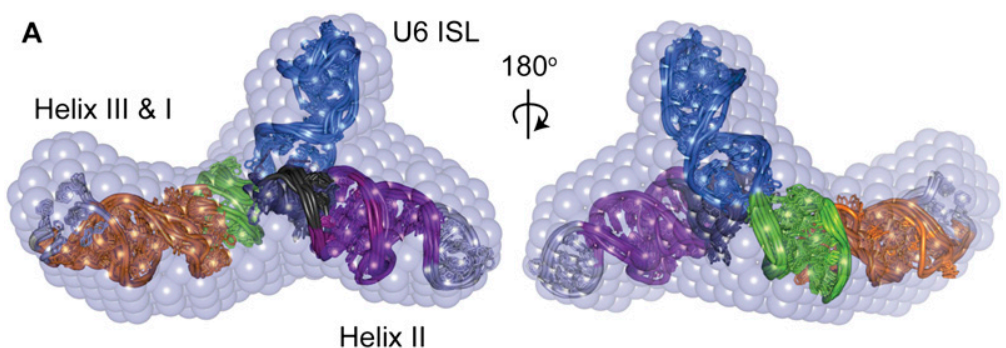

B

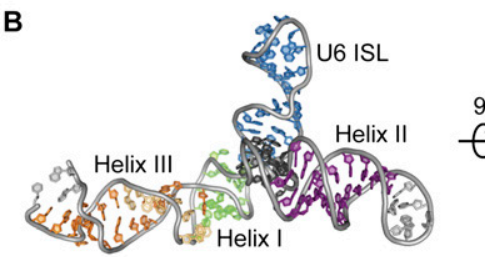

C

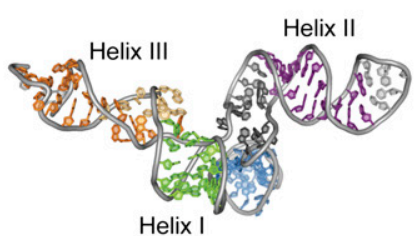

D

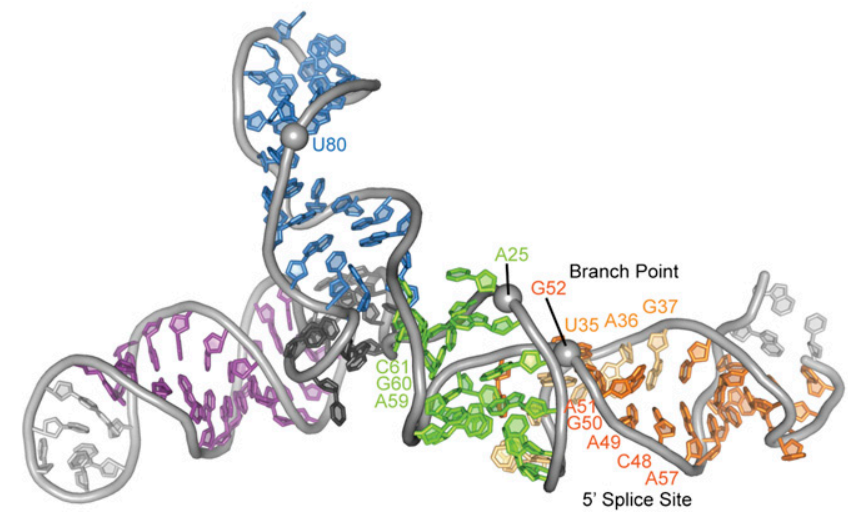

FIGURE 7. The U2/U6 complex assumes an extended conformation in solution. (A) The 10 lowest-energy refined structural models have an overall backbone RMSD of 1.9 A. Structural features are color-coded as in Figure 1. The models agree well with the ab initio structure of U2/U6 (pale blue). (B) Lowest-energy refined structural model of U2/U6. (C) The U-rich loop of the three-helix junction tucks underneath the base of the U6 ISL, resulting in a zigzag shape between Helices II and III. (D) The phosphates of the U80 metal binding site and residues U6-G52 and U2-A24 are shown as space-filling. The AGC triad (U6 residues 59-61) and residues in the $5^{\prime}$ splice site (U6-47 to 51) and branch point (U2-33 to 38) recognition sequences are labeled.

this relatively large molecule in solution using sparse NMR data and SAXS. Determination of the free U2/U6 structure provides the relative configuration of essential RNA components in the absence of proteins and may provide insight into the structural and functional role of other essential splicing factors necessary for formation of the spliceosomal active site.

\section{MATERIALS AND METHODS}

\section{RNA sample preparation}

RNA was transcribed in vitro using purified $\mathrm{His}_{6}$-tagged T7 RNA polymerase. DNA templates were prepared through phosphorylation and ligation of short complementary, overlapping oligonucleotides (Integrated DNA Technologies) into a pUC19 vector (New England Biolabs). A BsaI restriction site was included at the end of the template to allow for run-off transcription after digestion with
BsaI enzyme (NEB). ${ }^{13} \mathrm{C}-{ }^{15} \mathrm{~N}$ labeled samples of $\mathrm{U} 2 / \mathrm{U} 6$ were prepared using ${ }^{13} \mathrm{C}-{ }^{15} \mathrm{~N}$ labeled nucleotides (Cambridge Isotope Laboratories). RNA samples were purified using denaturing $8 \%$ PAGE with $8 \mathrm{M}$ urea. Impurities were removed by DEAE anion exchange (Bio-Rad) using a low-salt buffer $(20 \mathrm{mM}$ Tris- $\mathrm{HCl}$ at $\mathrm{pH}$ 7.6, $200 \mathrm{mM}$ sodium chloride) to wash and a high-salt buffer $(20 \mathrm{mM}$ Tris- $\mathrm{HCl}$ at $\mathrm{pH}$ 7.6, 1.5 M sodium chloride) to elute the RNA. Samples were then ethanolprecipitated and resuspended at a concentration of $<5 \mathrm{mg} / \mathrm{mL}$. The RNA was refolded by heating to $90^{\circ} \mathrm{C}$ and cooling quickly on ice, and samples were dialyzed for 16-24 h in 10 $\mathrm{mM}$ potassium phosphate $(\mathrm{pH} 7.0)$ in 0 or 2 $\mathrm{mM}$ magnesium chloride (NMR samples) or $50 \mathrm{mM}$ Tris- $\mathrm{HCl}$ ( $\mathrm{pH} 7.0$ ); $150 \mathrm{mM}$ sodium chloride; and 0,2 , or $10 \mathrm{mM}$ magnesium chloride (SAXS samples). All samples were assayed for folding homogeneity by $6 \%$ nondenaturing PAGE.

\section{NMR data collection}

All spectra were obtained on Bruker Avance or Varian Inova spectrometers equipped with cryogenic single $z$-axis gradient $\mathrm{HCN}$ probes at the National Magnetic Resonance Facility at Madison. Resonances were assigned using ${ }^{1} \mathrm{H}-{ }^{1} \mathrm{H} 2 \mathrm{D}$ NOESY with a mixing time of 100 msec and ${ }^{1} \mathrm{H}-{ }^{15} \mathrm{~N}$ 2D TROSY-HSQC experiments and by reference to previously determined chemical shifts for helical domains (BMRB entry 6320 and 17972). Partial alignment for RDC measurements was achieved by addition of $10 \mathrm{mg} / \mathrm{mL}$ Pf1 filamentous bacteriophage (ASLA) to a ${ }^{13} \mathrm{C},{ }^{15} \mathrm{~N}$ Gand U-labeled sample. Pf1 phage concentration was confirmed by measuring ${ }^{2} \mathrm{H}$ splitting at $700 \mathrm{MHz}$. Imino ${ }^{1} \mathrm{H}$ RDC measurements were obtained using a ${ }^{1} \mathrm{H}-{ }^{15} \mathrm{~N}$ TROSY-HSQC experiment. $\mathrm{RDC}$ measurements were in the range of -8.0 to $+26.4 \mathrm{~Hz}$.

\section{Structure determination of Helix I}

The structure of Helix I was characterized in the context of the 111-nt RNA as well as an isolated 24-nt RNA construct. The 24-nt Helix I RNA contains the Helix Ia and Helix Ib sequences from Saccharomyces cerevisiae connected by a GAAA tetraloop and stabilized by an additional GC pair on Helix Ib as follows: 5'-GGCUUA GAUCAGAAAUGAUCAGCC- 3 '. The RNA sample was prepared in the same manner as the 111-nt U2/U6 RNA. The structure of Helix I was solved by NMR in low ionic strength at $\mathrm{pH}$ 7.0. NOE restraints were measured from ${ }^{1} \mathrm{H}-{ }^{1} \mathrm{H} 2 \mathrm{D}$ NOESY spectra with a mixing time of $150 \mathrm{msec}$ (exchangeable protons) and $350 \mathrm{msec}$ (nonexchangeable protons). NOE cross-peaks were semiquantitatively binned to three categories based on peak intensity: strong (1.8-3.0 $\AA$ ), medium (2.0-4.5 $\AA$ ), and weak (3.0-5.5 $)$ ). Torsion angle restraints for A-form helical regions were set to standard values 
$\left( \pm 15^{\circ}\right) . \mathrm{C} 2^{\prime}$-endo sugar pucker was detected by total correlation spectroscopy (TOCSY). Sugar pucker conformations for residues with weak $\mathrm{H} 1^{\prime}-\mathrm{H} 2^{\prime}$ couplings were left unrestricted. Initial structures were calculated using CNS 1.1 (Brunger et al. 1998) as described (Sashital et al. 2003). The 10 lowest-energy out of 50 structures were refined using XPLOR-NIH (Schwieters et al. 2003) with $42 \mathrm{RDC}$ restraints.

\section{SAXS data collection}

All SAXS data were obtained at Sector 12 of the Advanced Photon Source at Argonne National Laboratory. Measurements were carried out in $50 \mathrm{mM}$ Tris ( $\mathrm{pH} 7.0$ ); $150 \mathrm{mM}$ sodium chloride; and $0 \mathrm{mM}, 2 \mathrm{mM}$, or $10 \mathrm{mM}$ magnesium chloride. RNA samples were loaded into a 1-mm capillary and flowed back and forth throughout the exposure. Twenty data collections of $0.5 \mathrm{sec}$ each were averaged for each sample and buffer. The scattering intensity was obtained by subtracting the background scattering from the sample scattering. Buffer matching was determined by adjusting subtraction of wide-angle scattering (WAXS) until the contribution from buffer scattering was negligible. The scattering intensity at $q=0 \AA^{-1}[I(0)]$, as determined by Guinier analysis, was compared between four different concentrations $(0.5,1.0,2.0$, and 3.0 $\mathrm{mg} / \mathrm{mL}$ ) to detect possible interparticle interactions. WAXS and SAXS data were merged using the region between $q=0.09 \AA^{-1}$ and $0.17 \AA^{-1}$. Samples were assayed for radiation damage by denaturing $8 \%$ PAGE after data collection. No radiation damage was detected (data not shown).

\section{Ab initio structure calculation}

All SAXS data were processed using GNOM (Svergun 1992) to obtain the pair distance distribution function (PDDF) and extrapolate the scattering curve to $I(0)$. $D_{\max }$ was calibrated in increments of $2 \AA$ until the PDDF curve fell smoothly to zero. The GNOM output was then used with DAMMIF (Franke and Svergun 2009) to calculate 20 dummy atom models. Models were averaged using the program DAMAVER (Volkov and Svergun 2003), with a resulting normalized spatial discrepancy (NSD) of between 0.7 and 0.9 , indicating good agreement between individual models. Finally, smooth envelope models were generated using the SITUS software (Wriggers 2010). Ab initio structures were superimposed using the Supcomb program (Kozin and Svergun 2000).

\section{Molecular modeling and refinement}

Three-dimensional (3D) models of each isolated helix and stem-loop in U2/U6 consistent with the NMR-determined secondary structure were created using the MC-Fold/MC-Sym pipeline (Parisien and Major 2008). The three-helix junction was generated in three steps using the relation capabilities of MC-Sym (Gautheret et al. 1993). Helices were then built onto the junction region in MC-Sym. The small-angle X-ray scattering amplitudes of 2500 of the models were predicted using the FOXS web server (Schneidman-Duhovny et al. 2010). Agreement to the experimental SAXS amplitudes was measured using $\chi^{2}$ goodness-of-fit analysis. All but the $25 \%$ of models with the lowest $\chi^{2}$ values were discarded. The best models were sorted by fit to 18 experimental RDC measurements from imino ${ }^{1} \mathrm{H}-{ }^{15} \mathrm{~N}$ couplings as determined using the PALES/DC software (Zweckstetter and Bax 2000). The models with a Q factor of $<0.35$ were chosen for further refinement. Covalent connectivity was restored for these 10 models using the AMBER force field (Open MM Zephyr software) (Friedrichs et al. 2009). Normal mode analysis was performed for all 10 models as previously described (Kazantsev et al. 2011) using the elNémo server (Suhre and Sanejouand 2004). The resulting perturbed models were sorted again as described above. The selected models were then refined against SAXS data, RDC measurements, and base-pairing restraints in XPLOR-NIH as previously described (Zuo et al. 2010). Distance restraints based on the previously determined U6 ISL structure (Venditti et al. 2009) were incorporated on the basis of chemical shift similarity between the U6 ISL construct and the 111-nt U2/U6 construct. Distance and dihedral angle restraints based on A-form helical geometry were incorporated for Helices I, II, and III. P-P distances $(5.4 \pm 0.5 \AA)$ were included for singlestranded regions to help maintain pseudo-A-form geometry and prevent the backbone phosphate groups from moving too close during molecular dynamics simulations in the absence of other restraints. P-P envelope size restraints were also incorporated based on the overall size of the ab initio structure.

\section{Coordinates}

Coordinates for Helix I and the 111-nt U2/U6 complex have been deposited into the Protein Data Bank (accession code 2LK3 for Helix I and 2LKR for U2/U6). NMR chemical shift assignments and restraint files for Helix I have been deposited into the BioMagResBank (accession code 17972). Chemical shift assignments in the absence and presence of $\mathrm{MgCl}_{2}$ and restraint files for $\mathrm{U} 2 / \mathrm{U} 6$ have also been deposited into the BioMagResBank (accession code 17961).

\section{ACKNOWLEDGMENTS}

We thank Lawrence Clos II, Marco Tonelli, and the National Magnetic Resonance Facility at Madison (NMRFAM) staff as well as Soenke Seifert and the Advanced Photon Source (APS) staff for technical support. We also thank David Brow, Alex Grishaev, and all the members of the Butcher laboratory for helpful discussions. This study made use of the National Magnetic Resonance Facility at Madison, which is supported by NIH grants P41RR02301 (BRTP/ NCRR) and P41GM66326 (NIGMS). Additional equipment was purchased with funds from the University of Wisconsin, the NIH (RR02781, RR08438), the NSF (DMB-8415048, OIA-9977486, BIR9214394), and the USDA. Use of the Advanced Photon Source, an Office of Science User Facility operated for the U.S. Department of Energy (DOE) Office of Science by Argonne National Laboratory, was supported by the U.S. DOE under Contract No. DE-AC0206CH11357. J.E.B. was supported by NIH Predoctoral training grant T32 GM07215-34. This work was supported by NIH grant GM065166 to S.E.B.

Received October 26, 2011; accepted December 16, 2011.

\section{REFERENCES}

Bax A, Cornilescu G, Marquardt JL, Ottiger M. 1998. Validation of protein structure from anisotropic carbonyl chemical shifts in a dilute liquid crystalline phase. J Am Chem Soc 120: 6836-6837.

Blad H, Reiter NJ, Abildgaard F, Markley JL, Butcher SE. 2005. Dynamics and metal ion binding in the U6 RNA intramolecular stem-loop as analyzed by NMR. J Mol Biol 353: 540-555. 
Brunger AT, Adams PD, Clore GM, DeLano WL, Gros P, GrosseKunstleve RW, Jiang JS, Kuszewski J, Nilges M, Pannu NS, et al. 1998. Crystallography \& NMR system: A new software suite for macromolecular structure determination. Acta Crystallogr D Biol Crystallogr 54: 905-921.

Butcher SE. 2009. The spliceosome as ribozyme hypothesis takes a second step. Proc Natl Acad Sci 106: 12211-12212.

Butcher SE, Brow DA. 2005. Towards understanding the catalytic core structure of the spliceosome. Biochem Soc Trans 33: 447-449.

Cao S, Chen SJ. 2006. Free energy landscapes of RNA/RNA complexes: With applications to snRNA complexes in spliceosomes. J Mol Biol 357: 292-312.

Collins CA, Guthrie C. 2000. The question remains: Is the spliceosome a ribozyme? Nat Struct Biol 7: 850-854.

Datta B, Weiner AM. 1991. Genetic evidence for base pairing between U2 and U6 snRNA in mammalian mRNA splicing. Nature 352: 821-824.

Du Z, Yu J, Ulyanov NB, Andino R, James TL. 2004. Solution structure of a consensus stem-loop D RNA domain that plays important roles in regulating translation and replication in enteroviruses and rhinoviruses. Biochemistry 43: 11959-11972.

Egecioglu DE, Chanfreau G. 2011. Proofreading and spellchecking: A two-tier strategy for pre-mRNA splicing quality control. RNA 17: 383-389.

Fabrizio P, Dannenberg J, Dube P, Kastner B, Stark H, Urlaub H, Luhrmann R. 2009. The evolutionarily conserved core design of the catalytic activation step of the yeast spliceosome. Mol Cell 36: 593-608.

Fortner DM, Troy RG, Brow DA. 1994. A stem/loop in U6 RNA defines a conformational switch required for pre-mRNA splicing. Genes Dev 8: 221-233.

Franke D, Svergun DI. 2009. DAMMIF, a program for rapid ab-initio shape determination in small-angle scattering. J Appl Crystallogr 42: $342-346$.

Friedrichs MS, Eastman P, Vaidyanathan V, Houston M, Legrand S, Beberg AL, Ensign DL, Bruns CM, Pande VS. 2009. Accelerating molecular dynamic simulation on graphics processing units. J Comput Chem 30: 864-872.

Gautheret D, Major F, Cedergren R. 1993. Modeling the threedimensional structure of RNA using discrete nucleotide conformational sets. J Mol Biol 229: 1049-1064.

Gordon PM, Piccirilli JA. 2001. Metal ion coordination by the AGC triad in domain 5 contributes to group II intron catalysis. Nat Struct Biol 8: 893-898.

Gordon PM, Sontheimer EJ, Piccirilli JA. 2000. Metal ion catalysis during the exon-ligation step of nuclear pre-mRNA splicing: Extending the parallels between the spliceosome and group II introns. RNA 6: 199-205.

Grishaev A, Ying J, Canny MD, Pardi A, Bax A. 2008. Solution structure of tRNAVal from refinement of homology model against residual dipolar coupling and SAXS data. J Biol NMR 42: 99-109.

Guo Z, Karunatilaka KS, Rueda D. 2009. Single-molecule analysis of protein-free U2-U6 snRNAs. Nat Struct Mol Biol 16: 1154-1159.

Han H, Dervan PB. 1994. Visualization of RNA tertiary structure by RNA-EDTA.Fe(II) autocleavage: Analysis of tRNA ${ }^{\text {Phe }}$ with uridine-EDTA.Fe(II) at position 47. Proc Natl Acad Sci 91: 49554959.

Hausner TP, Giglio LM, Weiner AM. 1990. Evidence for base-pairing between mammalian U2 and U6 small nuclear ribonucleoprotein particles. Genes Dev 4: 2146-2156.

Hilliker AK, Staley JP. 2004. Multiple functions for the invariant AGC triad of U6 snRNA. RNA 10: 921-928.

Huppler A, Nikstad LJ, Allmann AM, Brow DA, Butcher SE. 2002. Metal binding and base ionization in the U6 RNA intramolecular stem-loop structure. Nat Struct Biol 9: 431-435.

Kazantsev AV, Rambo RP, Karimpour S, Santalucia J Jr, Tainer JA, Pace NR. 2011. Solution structure of RNase P RNA. RNA 17: 1159-1171.

Keating KS, Toor N, Perlman PS, Pyle AM. 2010. A structural analysis of the group II intron active site and implications for the spliceosome. RNA 16: 1-9.
Konarska MM, Vilardell J, Query CC. 2006. Repositioning of the reaction intermediate within the catalytic center of the spliceosome. Mol Cell 21: 543-553.

Kozin MB, Svergun DI. 2000. Automated matching of high- and lowresolution structural models. J Appl Crystallogr 34: 33-41.

Lee C, Jaladat Y, Mohammadi A, Sharifi A, Geisler S, Valadkhan S. 2010. Metal binding and substrate positioning by evolutionarily invariant U6 sequences in catalytically active protein-free snRNAs. RNA 16: 2226-2238.

Lescoute A, Westhof E. 2006. Topology of three-way junctions in folded RNAs. RNA 12: 83-93.

Li CF, Costa M, Michel F. 2011. Linking the branchpoint helix to a newly found receptor allows lariat formation by a group II intron. EMBO J 30: 3040-3051.

Luukkonen BG, Seraphin B. 1998. Genetic interaction between U6 snRNA and the first intron nucleotide in Saccharomyces cerevisiae. RNA 4: 167-180.

Madhani HD, Guthrie C. 1992. A novel base-pairing interaction between U2 and U6 snRNAs suggests a mechanism for the catalytic activation of the spliceosome. Cell 71: 803-817.

Madhani HD, Guthrie C. 1994. Randomization-selection analysis of snRNAs in vivo: Evidence for a tertiary interaction in the spliceosome. Genes Dev 8: 1071-1086.

Madhani HD, Bordonne R, Guthrie C. 1990. Multiple roles for U6 snRNA in the splicing pathway. Genes Dev 4: 2264-2277.

Mefford MA, Staley JP. 2009. Evidence that U2/U6 helix I promotes both catalytic steps of pre-mRNA splicing and rearranges in between these steps. RNA 15: 1386-1397.

Padgett RA, Konarska MM, Grabowski PJ, Hardy SF, Sharp PA. 1984. Lariat RNA's as intermediates and products in the splicing of messenger RNA precursors. Science 225: 898-903.

Parisien M, Major F. 2008. The MC-Fold and MC-Sym pipeline infers RNA structure from sequence data. Nature 452: 51-55.

Reiter NJ, Nikstad LJ, Allmann AM, Johnson RJ, Butcher SE. 2003. Structure of the U6 RNA intramolecular stem-loop harboring an $\mathrm{S}(\mathrm{P})$-phosphorothioate modification. RNA 9: 533-542.

Reyes JL, Gustafson EH, Luo HR, Moore MJ, Konarska MM. 1999. The C-terminal region of hPrp8 interacts with the conserved GU dinucleotide at the $5^{\prime}$ splice site. RNA 5: 167-179.

Rhode BM, Hartmuth K, Westhof E, Luhrmann R. 2006. Proximity of conserved U6 and U2 snRNA elements to the 5' splice site region in activated spliceosomes. EMBO J 25: 2475-2486.

Ryan DE, Kim CH, Murray JB, Adams CJ, Stockley PG, Abelson J. 2004. New tertiary constraints between the RNA components of active yeast spliceosomes: A photo-crosslinking study. RNA 10: 1251-1265.

Sashital DG, Allmann AM, Van Doren SR, Butcher SE. 2003. Structural basis for a lethal mutation in U6 RNA. Biochemistry 42: 1470-1477.

Sashital DG, Cornilescu G, McManus CJ, Brow DA, Butcher SE. 2004. U2-U6 RNA folding reveals a group II intron-like domain and a four-helix junction. Nat Struct Mol Biol 11: 1237-1242.

Schneidman-Duhovny D, Hammel M, Sali A. 2010. FoXS: A web server for rapid computation and fitting of SAXS profiles. Nucleic Acids Res 38: W540-W544.

Schwieters CD, Kuszewski JJ, Tjandra N, Clore GM. 2003. The XplorNIH NMR molecular structure determination package. J Magn Reson 160: 65-73.

Smith DJ, Query CC, Konarska MM. 2008. "Nought may endure but mutability": Spliceosome dynamics and the regulation of splicing. Mol Cell 30: 657-666.

Sontheimer EJ, Sun S, Piccirilli JA. 1997. Metal ion catalysis during splicing of premessenger RNA. Nature 388: 801-805.

Steitz TA, Steitz JA. 1993. A general two-metal-ion mechanism for catalytic RNA. Proc Natl Acad Sci 90: 6498-6502.

Suhre K, Sanejouand YH. 2004. ElNemo: A normal mode web server for protein movement analysis and the generation of templates for molecular replacement. Nucleic Acids Res 32: W610-W614.

Sun JS, Manley JL. 1995. A novel U2-U6 snRNA structure is necessary for mammalian mRNA splicing. Genes Dev 9: 843-854. 
Svergun DI. 1992. Determination of the regularization parameter in indirect-transform methods using perceptual criteria. J Appl Crystallogr 25: 495-503.

Theimer CA, Finger LD, Trantirek L, Feigon J. 2003. Mutations linked to dyskeratosis congenita cause changes in the structural equilibrium in telomerase RNA. Proc Natl Acad Sci 100: 449-454.

Toor N, Keating KS, Taylor SD, Pyle AM. 2008. Crystal structure of a self-spliced group II intron. Science 320: 77-82.

Valadkhan S, Jaladat Y. 2010. The spliceosomal proteome: At the heart of the largest cellular ribonucleoprotein machine. Proteomics 10: $4128-4141$.

Valadkhan S, Manley JL. 2000. A tertiary interaction detected in a human U2-U6 snRNA complex assembled in vitro resembles a genetically proven interaction in yeast. RNA 6: 206-219.

Valadkhan S, Manley JL. 2001. Splicing-related catalysis by proteinfree snRNAs. Nature 413: 701-707.

Valadkhan S, Manley JL. 2003. Characterization of the catalytic activity of U2 and U6 snRNAs. RNA 9: 892-904.

Valadkhan S, Mohammadi A, Wachtel C, Manley JL. 2007. Proteinfree spliceosomal snRNAs catalyze a reaction that resembles the first step of splicing. RNA 13: 2300-2311.

Valadkhan S, Mohammadi A, Jaladat Y, Geisler S. 2009. Protein-free small nuclear RNAs catalyze a two-step splicing reaction. Proc Natl Acad Sci 106: 11901-11906.

Venditti V, Clos L II, Niccolai N, Butcher SE. 2009. Minimum-energy path for a u6 RNA conformational change involving protonation, base-pair rearrangement and base flipping. J Mol Biol 391: 894905.

Vidal VP, Verdone L, Mayes AE, Beggs JD. 1999. Characterization of U6 snRNA-protein interactions. RNA 5: 1470-1481.

Volkov VV, Svergun DI. 2003. Uniqueness of ab initio shape determination in small-angle scattering. J Appl Crystallogr 36: 860-864.
Wahl MC, Will CL, Luhrmann R. 2009. The spliceosome: Design principles of a dynamic RNP machine. Cell 136: 701-718.

Wang J, Zuo X, Yu P, Xu H, Starich MR, Tiede DM, Shapiro BA, Schwieters CD, Wang YX. 2009. A method for helical RNA global structure determination in solution using small-angle X-ray scattering and NMR measurements. J Mol Biol 393: 717-734.

Wassarman DA, Steitz JA. 1992. Interactions of small nuclear RNA's with precursor messenger RNA during in vitro splicing. Science 257: 1918-1925.

Wriggers W. 2010. Using situs for the integration of multi-resolution structures. Biophys Rev 2: 21-27.

Xia T, SantaLucia J Jr, Burkard ME, Kierzek R, Schroeder SJ, Jiao X, Cox C, Turner DH. 1998. Thermodynamic parameters for an expanded nearest-neighbor model for formation of RNA duplexes with Watson-Crick base pairs. Biochemistry 37: 14719-14735.

Yean SL, Wuenschell G, Termini J, Lin RJ. 2000. Metal-ion coordination by U6 small nuclear RNA contributes to catalysis in the spliceosome. Nature 408: 881-884.

Yu YT, Maroney PA, Darzynkiwicz E, Nilsen TW. 1995. U6 snRNA function in nuclear pre-mRNA splicing: A phosphorothioate interference analysis of the U6 phosphate backbone. RNA 1: 4654.

Zuker M. 2003. Mfold web server for nucleic acid folding and hybridization prediction. Nucleic Acids Res 31: 3406-3415.

Zuo X, Wang J, Yu P, Eyler D, Xu H, Starich MR, Tiede DM, Simon AE, Kasprzak W, Schwieters CD, et al. 2010. Solution structure of the cap-independent translational enhancer and ribosome-binding element in the 3' UTR of turnip crinkle virus. Proc Natl Acad Sci 107: 1385-1390.

Zweckstetter M, Bax A. 2000. Prediction of sterically induced alignment in a dilute liquid crystalline phase: Aid to protein structure determination by NMR. J Am Chem Soc 122: 3791-3792. 

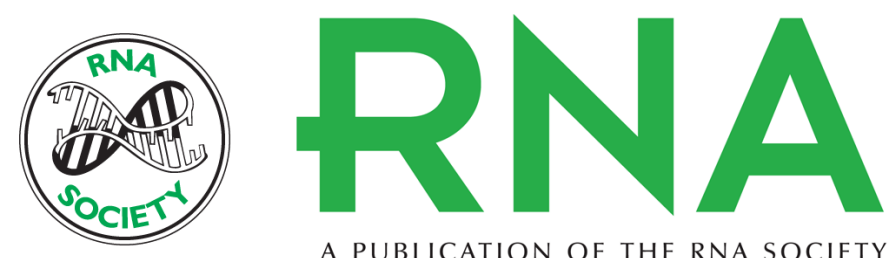

A PUBLICATION OF THE RNA SOCIETY

\title{
Structure of the yeast U2/U6 snRNA complex
}

\author{
Jordan E. Burke, Dipali G. Sashital, Xiaobing Zuo, et al.
}

RNA 2012 18: 673-683 originally published online February 10, 2012

Access the most recent version at doi:10.1261/rna.031138.111

\section{References This article cites 72 articles, 31 of which can be accessed free at: http://rnajournal.cshlp.org/content/18/4/673.full.html\#ref-list-1}

\section{License}

Email Alerting Receive free email alerts when new articles cite this article - sign up in the box at the Service top right corner of the article or click here. 